\title{
Identification of disinfection by-products (DBPs) halo phenols in drinking water
}

\author{
Ramarajan Selvam $^{1} \cdot$ Selvakumar Muniraj $^{1} \cdot$ Tamilselvi Duraisamy $^{1} \cdot$ Vasanthy Muthunarayanan $^{1}$ (D)
}

Received: 21 May 2018 / Accepted: 20 July 2018 / Published online: 7 August 2018

(C) The Author(s) 2018

\begin{abstract}
The Bureau of Indian Standard (BIS, New Delhi) has framed a set of standards for drinking water description (IS 10500:1991http://www.indiawaterportal.org), which has specifications drawn up in 1983 with the most current amendment (July, 2010), and the US Environmental Protection Agency (USEPA 2003) has also developed policy for different drinking water disinfection by-products (DBPs). This study examined the quality of metropolitan drinking water by monitoring the physicochemical parameters, and DBPs study such as the effects of halide ions, natural organic matter, and drinking water characterization were investigated. The sampled water had halo phenols DBPs as a result of disinfection, during chlorination. The water was alkaline in nature, and the water temperature varied from 33 to $37^{\circ} \mathrm{C}$. The major ions, namely bromate, iodate, chlorite, chromate, sulfate and phosphate, have been investigated in the municipality drinking water, Tiruchirappalli and Srirangam in Tamil Nadu, India. Here, three solvents such as hexane, petroleum ether and pentane were used for the liquid-liquid extraction of target compounds. The gas chromatographs equipped with capillary columns (DB-WAX) were employed for the determination of DBPs and 2-bromo-4-chlorophenol was predominantly identified.
\end{abstract}

Keywords DBPs $\cdot$ Water $\cdot$ Total organic carbon $\cdot$ Solvents $\cdot$ DB-WAX $\cdot$ GCMS

\section{Introduction}

Water is the prime need for all living entities on Earth. Water resources have been obstinately affected by rapid development and increased anthropogenic activities. WHO (2003) estimates that, in India, about 38 million people are affected by waterborne diseases through various means each year, among which over $75 \%$ are children. So, disinfection of drinking water is essential to reduce the incidence and spread of waterborne diseases (Gaffga et al. 2007). The disinfection of metropolitan drinking water is performed with chlorine in order to ensure the health of the public and to protect the people against various waterborne infirmities (Villanueva et al. 2015). Chlorination is the most universally accepted method for disinfection since the early twentieth century (Paull and Barron 2004) as it prevents the contamination of potable water against pathogens like

Vasanthy Muthunarayanan

vasanthy@bdu.ac.in

1 Department of Environmental Biotechnology, School of Environmental Sciences, Bharathidasan University, Tiruchirappalli 620024, India bacteria and viruses (Zha et al. 2014). In (1974), Rook first discovered that hypochlorous and hypobromous acid react with naturally present organic matter to form water DBPs, few trihalomethanes (THM) substances such as chloroform $\left(\mathrm{CHCl}_{3}\right)$, bromo dichloromethane $\left(\mathrm{CHCl}_{2} \mathrm{Br}\right)$, dibromo chloromethane $\left(\mathrm{CHClBr}_{2}\right)$ and bromoform $\left(\mathrm{CHBr}_{3}\right)$. Richardson (2002) reported that during the addition of chlorine to water, toxic compounds are formed and more than 600 DBPs were identified like haloacetic acids. DBPs are formed through the reaction of organic precursor (natural organic matter, algal organic matter, wastewater effluent organic matter) and inorganic substance (bromate, iodate and nitrate) and also on reaction with chemical disinfectants (chlorine, chlorine dioxide, chloramines and ozone) (Krasner 2009). NOM includes humic substances, fulvic acid, hydrophilic amino acids (Ser, Thr, Asn, Gln, His, Tyr), carboxylic acids and carbohydrates too (Kitis et al. 2001). The USEPA issued the DBPs rule that specifies that the highest TOC levels for treated water is 2 and $4 \mathrm{mg} / \mathrm{L}$ in source water to ensure that DBPs such as THMs are present at acceptable levels (Pontius 1993). Zeng et al. (2015) highlighted that the common genotoxic compounds come from raw water and several mutagenic or carcinogenic DBPs are formed due to addition 
of disinfectants to drinking water. Chorine- and brominecontaining compounds also cause carcinogenic, mutagenic or teratogenic effects on animal studies (Weisel et al. 1999). Zhai et al. (2014) reported that 2,4,6-tribromoresorcinol, 2,6-dibromo-4-nitrophenol, 2,2,4-tribromo-5-hydroxy4-cyclopentene-1,3-dione, 2,2,4-dibro-mochloro-5-hydroxy-4-cyclopentene-1,3-dione, and 2,2,4-bromo-dichloro5-hydroxy-4-cyclopentene-1,3-dione are termed as polar brominated DBPs.

The two most bountiful classes of DBPs are reported to be trihalo methanes (THMs) and haloacetic acids (HAAs) (Krasner et al. 1989). The prescribed maximum permissible level of THMs $\left(\mathrm{CHCl}_{3}, \mathrm{CHCl}_{2} \mathrm{Br}, \mathrm{CHClBr}_{2}\right.$ and $\left.\mathrm{CHBr}_{3}\right)$ is $<80 \mu \mathrm{g} / \mathrm{L}$ by USEPA and is $<100 \mu \mathrm{g} / \mathrm{L}$ by EU, and at the same time HAAs (monochloro, dichloro, trichloro, monobromo and dibromoacetic acids) recommended limit is $60 \mu \mathrm{g} / \mathrm{L}$. In case of bromate according to both the US and $\mathrm{EU}$, the permissible level is $10 \mu \mathrm{g} / \mathrm{L}$, and for chlorate and chlorite is $700 \mu \mathrm{g} / \mathrm{L}$ (USEPA 2006). Yang and Zhang (2013) reported the occurrence of brominated haloacetic acids, four new brominated DBPs such as 2,6-dibromo-4-nitrophenol, 2,4,6-tribromophenol, 3,5-dibromo-4-hydroxybenzaldehyde, and 3,5-dibromo-4-hydroxybenzoic acid and 5-bromosalicylic acid in chlorinated saline secondary and primary sewage effluents. Evidences have shown that brominated/iodinated DBPs generally are highly cytotoxic and genotoxic than their chlorinated analogs. And also Liu and Zhang (2014) reported the comparative toxicity of newly identified bromo- and iodo-phenolic DBPs to a marine alga such as 2,4,6-tri-iodophenol., 3,5-diiodo-4-hydroxybenzaldehyde., 2,4,6-tribromophenol., 2,6-diiodo-4-nitrophenol., 2,4-dibromophenol., 4-bromo-2-chlorophenol., 4-iodophenol., 3,5-dibromo-4-hydroxybenzaldehyde., 2-bromo4-chlorophenol., 2,4,6-trichlorophenol., 4-bromophenol., 2,4-dichlorophenol., 2,6-dibromo-4-nitrophenol, etc., during chlorination of the wastewater effluent. In drinking water, a measurable amount $(\mu \mathrm{g} / \mathrm{L})$ of 2-chlorophenol (00.00-0.065) and 4-chlorophenol (00.004-0.127) was measured (Sithole and Wiliams 1986). Chlorophenols are a group of compounds that are elaborated in a number of industries. Exposure to high levels of chlorophenols was reported to cause damage to the liver and immune system (ATSDR 1999). Jiang et al. (2017) has proposed a new method to reduce the DBP formation by ore treatment using GAC adsorption to remove the intermediate aromatic halogenated DBPs. Conventional methods used GAC adsorption to remove the NOM directly, whereas in this new approach the authors have claimed this method to be more effective in reducing the DBP formation than the traditional ones. India is facing a serious problem of natural resource insufficiency, especially that of water in view of population growth and urbanization. In India, there is no or very little awareness regarding the presence of DBPs in the drinking water and their toxic adverse effects and there are no specific reports regarding the presence of DBPs in southern Indian drinking waters. As this study is the first attempt in India, the prime aim was to identify and quantify the DBPs in the drinking water samples and to evaluate the physicochemical parameters of the same. This study would help in unraveling the presence of DBPs in the domestic supplies. The experiment was designed to collect water samples from Tiruchirappalli and Srirangam, Tamil Nadu, India. Drinking water samples obtained from the metropolitan tank was subjected to physicochemical characterization, estimation of bromate, iodate using UV-visible spectrophotometry followed by the GC-MS analysis for the identification of DBPs using three different solvents for extraction.

\section{Materials and methods}

\section{Sample collection}

Drinking water samples were collected from the metropolitan of Srirangam and Tiruchirappalli City, Tamil Nadu, India. Grab sampling methodology was followed (APHA 2005). The water samples collected before chlorination were maintained as the control.

\section{Study area}

Tiruchirappalli is situated in central southeastern India, almost at the geographic center of the state of Tamil Nadu (Fig. 1). The Cauvery Delta begins to form $16 \mathrm{~km}(9.9 \mathrm{mi})$ west of the city. Tiruchirappalli water supply entirely depends on river Cauvery. The schemes based on Cauvery River covers various areas of the city. The schemes originate from two stations, namely Tiruchirappalli $10.887012^{\circ} \mathrm{N}$, $78.721162^{\circ} \mathrm{E}$ and Srirangam $10.7904^{\circ} \mathrm{N}, 78.7057^{\circ} \mathrm{E}$.

\section{Reagents and chemicals}

All reagents used were of analytical grade from Merck, Loba Chemie, and GC-MS grade solvents such as petroleum ether, hexane and pentane were purchased from SigmaAldrich. All reagents used are verified to be contaminant free. All equipment and glassware used to analyze samples were verified to be carbon free and are combusted at $400{ }^{\circ} \mathrm{C}$ for a minimum of $4 \mathrm{~h}$.

\section{Physicochemical characterization of water samples}

The collected samples were analyzed for different physicochemical parameters such as $\mathrm{pH}, \mathrm{EC}$, alkalinity, hardness, calcium, magnesium, total solids (TS), total dissolved solids (TDS), total suspended solids (TSS), dissolved oxygen 


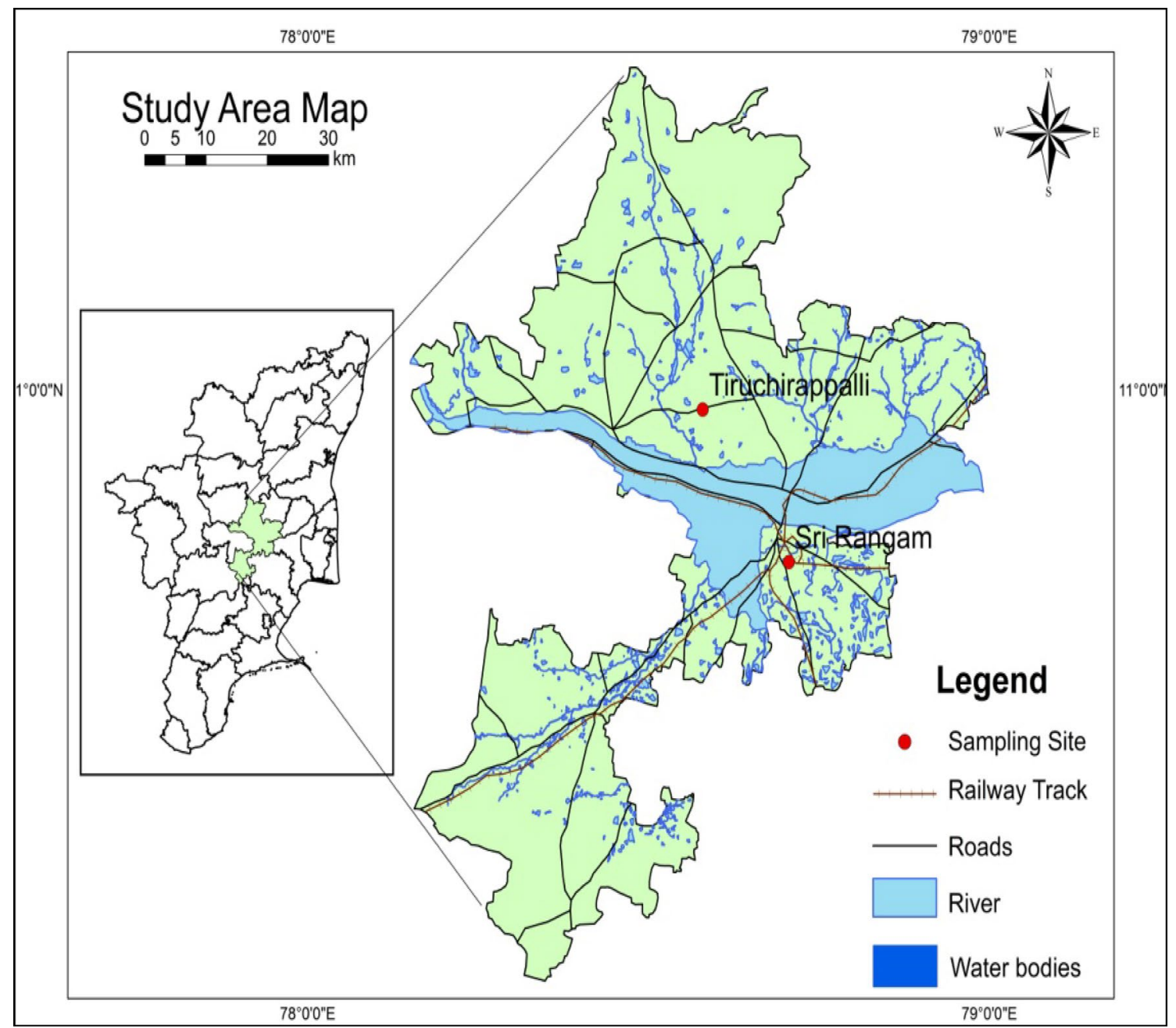

Fig. 1 Study area map

(DO), biological oxygen demand (BOD), chemical oxygen demand (COD), phosphate, sulfate, silicate and nitrate (APHA 2005).

\section{Measurement of TOC and anions}

The TOC test is used to determine the total organic carbon in an aqueous sample. The test of TOC utilizes heat and oxygen, ultraviolet radiation, chemical oxidants, or some combination of these methods to convert organic carbon to carbon dioxide which is measured with an infrared analyzer (Metcalf 2003). To determine the number of organically bound carbon, the organic molecules must be broken down to single carbon units and converted to a single molecular form that can be measured quantitatively (Prabhakaran et al. 2009). The TOC of the water samples was analyzed using TOC analyzer (Shimazdu model TOC-500), and the determination of anions (bromate, chromate, chlorite, iodate) was done using UV-Vis spectrophotometer (Spectropara-300).

\section{Selection of organic solvents}

The organic solvents are essential to improve the efficiency of extraction process. In this study, three extraction solvents were employed for the extraction of DBPs; the solvents were petroleum ether, hexane and pentane. EPA Method 551, Method 551.1, allows pentane to be applied as the extraction solvent and used to extract trihalomethanes, haloacetic acids, haloketones and chloropicrin (APHA 1995). Hexane and petroleum ether were used for the extraction of nonpolar compounds like aliphatic hydrocarbons, but petroleum ether contains lesser amount of aromatic compounds (Nawrocki 2013).

\section{Liquid-liquid extraction method}

Liquid-liquid extraction (LLE) is one of the most widely employed and useful technique for the DBPs sample preparation. However, infrequently large amounts of suspension 
are formed, and it is complicated to separate the solvent from the aqueous stage. Accurately $1000 \mathrm{~mL}$ of each sample was taken in separating funnel, and $50 \mathrm{~mL}$ of the three different types of solvent was added to three different separating funnels. The contents were mixed well for about 15-20 min until the solvents are separated. The 15-20 min duration is required for mixing.

\section{GC-MS analyses}

Hur et al. (2012) investigated the biodegradation-induced changes in the characteristics of dissolved organic matter (DOM) and the subsequent effects on disinfection by-product formation potentials (DBPFPs) of sewage water using GC equipped with a 30-m DB-WAX fused silica capillary column. In this study, to identify the DBPs the extract was subjected for GC-MS (SCION SQ/GC-MS; Type-8410; BR-5MS; BRUKER/45X GC44). Helium was employed as a carrier gas, initial oven temperature is $45^{\circ} \mathrm{C}$, maximum temperature is $270{ }^{\circ} \mathrm{C}$, initial time is $2 \mathrm{~min}$, rate is $25^{\circ} \mathrm{C} /$ min, final temperature is $260^{\circ} \mathrm{C}$, and final time is $10 \mathrm{~min}$. The gas chromatograph equipped with DB-WAX columns is one of which was polar type and fused silica capillary column (polyethylene glycol, $30 \mathrm{~m}$ long and $0.25 \mathrm{mmi}$.d., film thickness $0.25 \mu \mathrm{m})$. The column was operated using an injector port $\left(230^{\circ} \mathrm{C}\right)$, and the following oven temperature agenda was set as $40{ }^{\circ} \mathrm{C}$ for $4 \mathrm{~min}$, followed by an increase to $100{ }^{\circ} \mathrm{C}$ at a range of $4{ }^{\circ} \mathrm{C} / \mathrm{min}$ and as a final point ramped to $160{ }^{\circ} \mathrm{C}$.

\section{Results}

The physicochemical characteristics along with the anions and TOC were analyzed in the collected corporation drinking water sampled from Tiruchirappalli and Srirangam, Tamil Nadu (Table 1; Fig. 2).

\section{GC-MS}

The samples were subjected for GC-MS analysis, which include the water samples collected from Tiruchirappalli and Srirangam. They are selected as the representative of the schemes under investigation (Fig. 3). Table 2 elucidates GC-MS analysis of the chlorinated water samples using different liquid-liquid extractions, including pentane, hexane and petroleum ether. 4-Bromo-2-chlorophenol was detected during pentane extraction in chlorinated samples from Tiruchirappalli and Srirangam. The same compound was identified in hexane extraction of Srirangam. The water sample before chlorination was referred as control.
Table 1 Physicochemical characteristics of the metropolis water sample, Tiruchirappalli District

\begin{tabular}{lllccc}
\hline S. no & Parameters & Unit & Tiruchirappalli & Srirangam & Control \\
\hline 1 & $\mathrm{pH}$ & $\mathrm{pH}$ & $7.3 \pm 0.1$ & $7.6 \pm 0.1$ & $7.2 \pm 0.1$ \\
2 & $\mathrm{EC}$ & $\mathrm{mS} / \mathrm{cm}$ & $00.7 \pm 0.2$ & $01.2 \pm 0.0$ & $00.3 \pm 0.0$ \\
3 & $\mathrm{TS}$ & $\mathrm{mg} / \mathrm{L}$ & $630.3 \pm 5.0$ & $935.3 \pm 13.2$ & $370.3 \pm 13.2$ \\
4 & $\mathrm{TDS}$ & $\mathrm{mg} / \mathrm{L}$ & $201.6 \pm 3.7$ & $77.6 \pm 8.0$ & $147.0 \pm 8.0$ \\
5 & $\mathrm{TSS}$ & $\mathrm{mg} / \mathrm{L}$ & $90.0 \pm 0.0$ & $90.0 \pm 0.0$ & $80.0 \pm 0.0$ \\
6 & Alkalinity & $\mathrm{mg} / \mathrm{L}$ of $\mathrm{CaCO}_{3}$ & $67.3 \pm 1.1$ & $65.3 \pm 1.1$ & $79.3 \pm 1.1$ \\
7 & Hardness & $\mathrm{mg} / \mathrm{L}$ of $\mathrm{CaCO}_{3}$ & $48.3 \pm 0.5$ & $40.3 \pm 0.5$ & $35.0 \pm 0.5$ \\
8 & Calcium & $\mathrm{mg} / \mathrm{L}$ & $04.6 \pm 0.2$ & $06.0 \pm 0.2$ & $10.9 \pm 0.2$ \\
9 & Magnesium & $\mathrm{mg} / \mathrm{L}$ & $48.4 \pm 0.8$ & $53.1 \pm 1.4$ & $32.5 \pm 1.4$ \\
10 & Chloride & $\mathrm{mg} / \mathrm{L}$ & $02.3 \pm 0.02$ & $04.2 \pm 0.0$ & $03.4 \pm 0.0$ \\
11 & DO & $\mathrm{mg} / \mathrm{L}$ & $00.3 \pm 0.0$ & $00.8 \pm 0.0$ & $03.3 \pm 0.0$ \\
12 & BOD & $\mathrm{mg} / \mathrm{L}$ & $131.6 \pm 1.5$ & $144.0 \pm 1.7$ & $98.0 \pm 1.0$ \\
13 & COD & $\mathrm{mg} / \mathrm{L}$ & $04.1 \pm 0.0$ & $03.1 \pm 0.0$ & $00.4 \pm 0.0$ \\
14 & Phosphate & $\mathrm{mg} / \mathrm{L}$ & $01.4 \pm 0.0$ & $01.5 \pm 0.0$ & $00.7 \pm 0.0$ \\
15 & Sulfate & $\mathrm{mg} / \mathrm{L}$ & $90.0 \pm 0.0$ & $114.3 \pm 4.0$ & $64.6 \pm 4.0$ \\
16 & Silicate & $\mathrm{mg} / \mathrm{L}$ & $00.1 \pm 0.0$ & $00.4 \pm 0.0$ & $00.1 \pm 0.0$ \\
17 & Nitrate & $\mathrm{mg} / \mathrm{L}$ & $00.0 \pm 0.0$ & $00.0 \pm 0.0$ & $00.2 \pm 0.0$ \\
18 & Nitrite & $\mathrm{mg} / \mathrm{L}$ & $43.4 \pm 0.0$ & $44.1 \pm 0.0$ & $36.9 \pm 0.1$ \\
19 & TOC & $\mathrm{mg} / \mathrm{L}$ & $81.0 \pm 2.0$ & $74.0 \pm 1.0$ & $43.0 \pm 2.0$ \\
20 & Bromate & $\mu \mathrm{g} / \mathrm{L}$ & $52.0 \pm 1.2$ & $71.0 \pm 1.2$ & $24.0 \pm 1.2$ \\
21 & Chlorate & $\mu \mathrm{g} / \mathrm{L}$ & $90.0 \pm 0.2$ & $112.0 \pm 0.2$ & $76.0 \pm 0.2$ \\
22 & Iodate & $\mu \mathrm{g} / \mathrm{L}$ & $00.0 \pm 1.0$ & $00.0 \pm 2.0$ & $00.0 \pm 2.0$ \\
23 & Chromate & $\mu \mathrm{g} / \mathrm{L}$ & & &
\end{tabular}




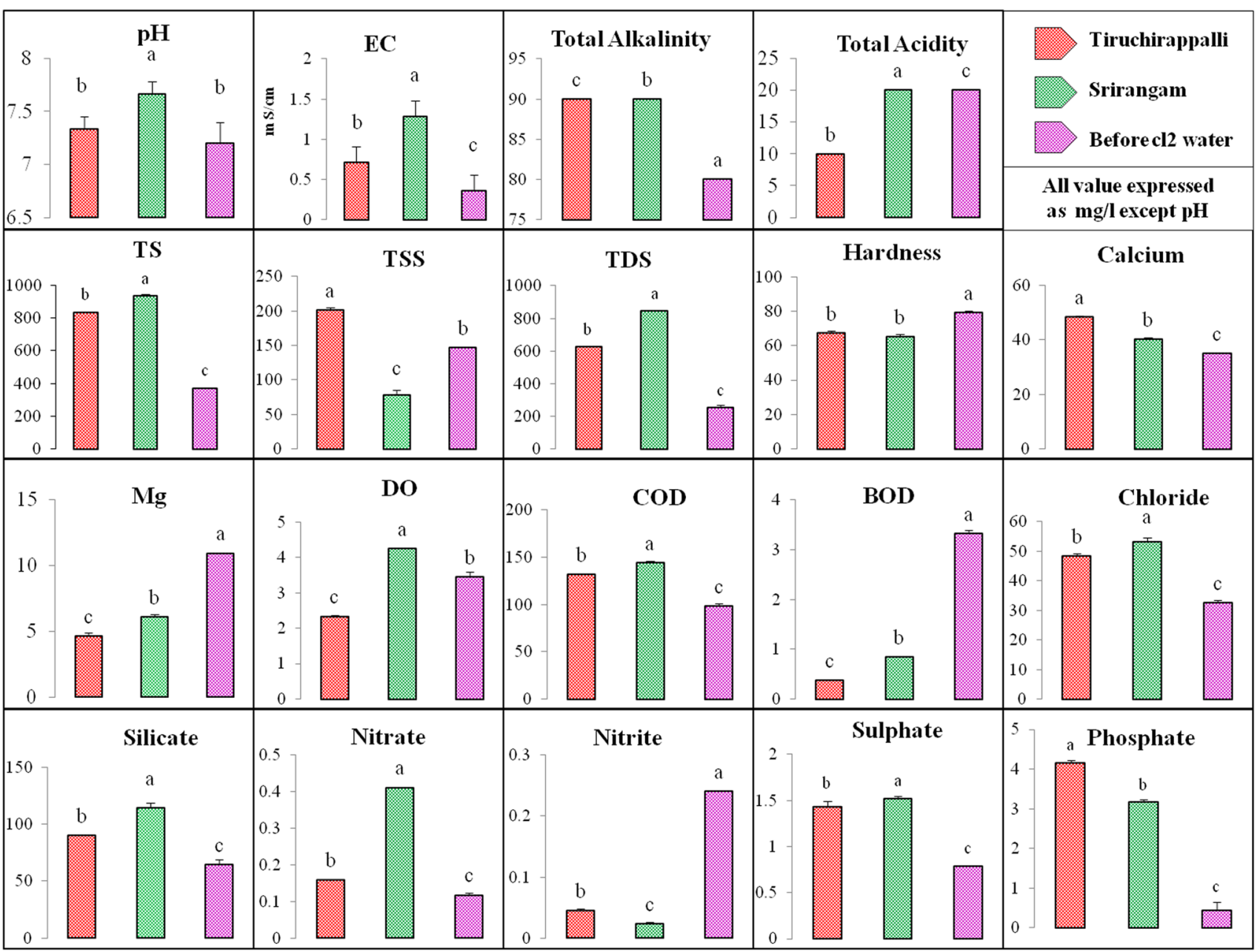

Fig. 2 Physicochemical characterization of drinking water samples. Values were expressed as mean $\pm \mathrm{SD}(N=3)$. Bar with different alphabets is significantly different from each other and with same alphabets has insignificant changes $(P<0.05)$. The physicochemical parameters $(\mathrm{pH}, \mathrm{EC}$, alkalinity, hardness, calcium, magnesium, TS, TDS, TSS, DO, BOD, COD, phosphate, sulfate, chloride, nitrite, sili- cate, nitrate, bromate, chlorite, iodate and chromate) concentration in drinking water at Tiruchirappalli and Srirangam; the parameter values were expressed as mean $\pm \mathrm{SD}(N=3)$. The figure noted that the bars represented by means of different alphabets are significantly different from each other and similar alphabets are insignificantly varied $(P \leq 0.05)$. Before chlorinated water referred as control

\section{Discussion}

The drinking waters supplied and distributed by local authorities or some private systems are termed as Public Water Supplies like metropolitan water. Accordingly, the selected place of Tiruchirappalli is situated in central southeastern India, almost at the geographic center of the state of Tamil $\mathrm{Nadu}$. It is formed and located in the river bank of Cauvery delta. At the same time, the Srirangam water source is located in the river banks of Kollidam River (Fig. 1). Hence, the slight variation is found in the physicochemical parameters both before and after chlorination. Consequently, several factors such as temperature, total organic carbon (TOC), $\mathrm{pH}$, bromate, chlorite and iodate concentrations were reported to significantly affect the formation of halo phenols compounds and in relation to the role of the water temperature on the DBPs formation in the metropolitan water $\left(33-37^{\circ} \mathrm{C}\right)$, as the higher temperatures promote the DBPs. Similarly, the higher range of $\mathrm{pH}(7.20-7.66)$ in Srirangam water might be the reason for the formation of alkaline ions (bicarbonate and carbonate ions) when considered with the Cauvery water. Chlorine reacts with humic substances (dissolved organic matter) present in most water supplies, forming a variety of halogenated DBPs such as THMs, HAAs, HANs, chloral hydrate and chloropicrin. It is commonly accepted that the reaction between chlorine and humic substances, a major component of NOM, is responsible for the production of organochlorine compounds during water treatment.

Most chlorinated DBPs are produced during oxidation and substitution reactions. The major functional groups of 


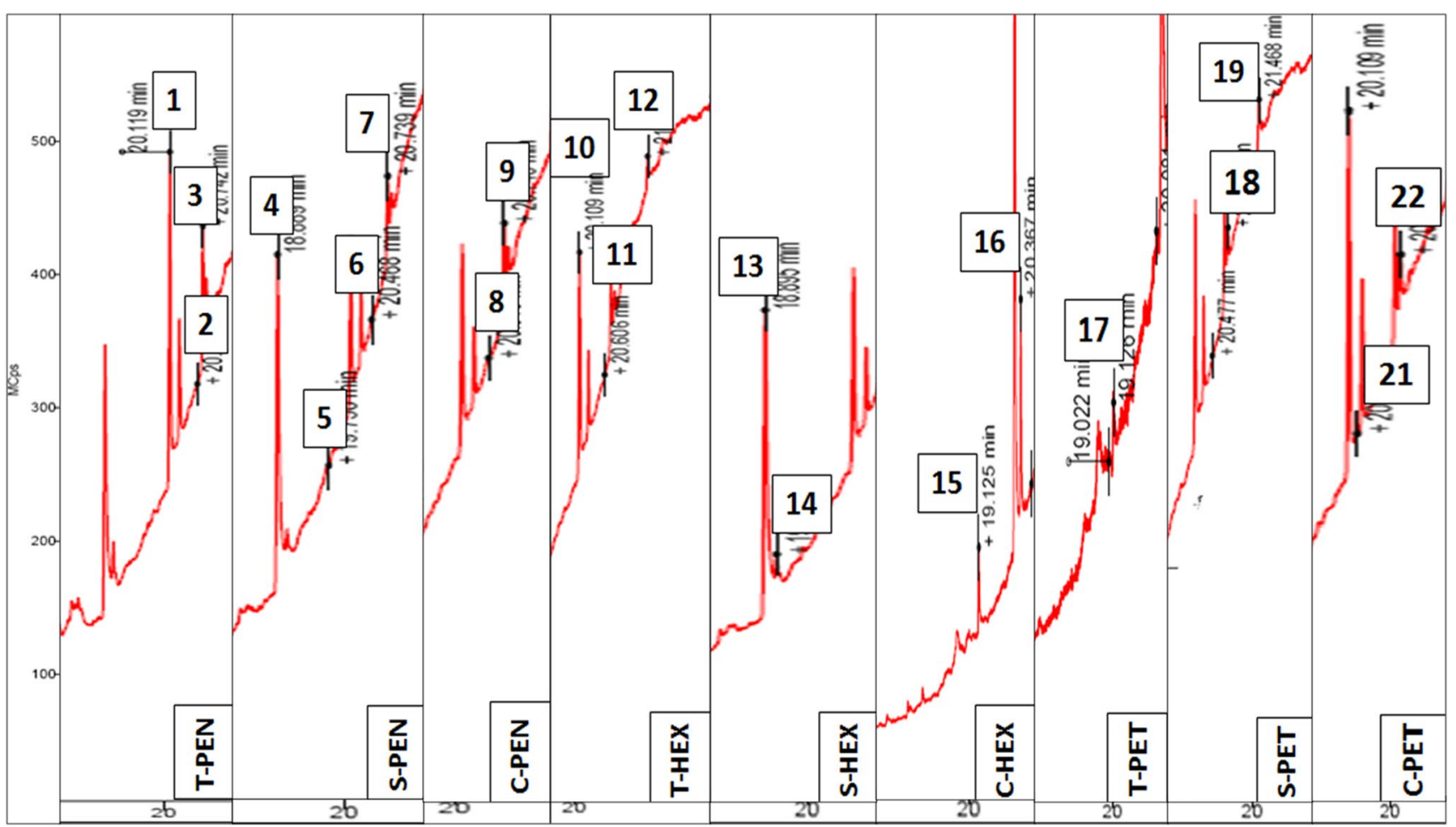

Fig. 3 Identification of halo phenols by gas chromatography and mass spectrophotometry. Note $T$ Tiruchirappalli, $S$ Srirangam, $C$ control (before chlorinated water), PEN pentane (solvents), HEX hexane (solvents), PET petroleum ether (solvents)

humic substances include acetyl, carboxyl, phenol, alcohol, carbonyl and methoxyl. The reactions proceed much more rapidly at high $\mathrm{pH}$. The formation of bromochlorophenol may be due to the reaction between the chlorine introduced in the form of hypochlorite with phenols to produce monochloro phenols or dichloro phenols or trichloro phenols (WHO 2004). The presence of bromate and chlorate was reported in both the drinking water samples. Nawrocki (2013) has also reported the concentration of bromate and chlorite as DBPs. In general, high-chlorine dosages were reported to result in the formation of chlorophenol and bromophenol. Ammonia, bromide and phenols were reported to facilitate higher consumption of $\mathrm{HOCl}$, thereby increasing the concentration of bromophenol (Acero et al. 2005). Also, the $\mathrm{pH}$ of the water would have also influenced the formation of bromochlorophenol. WHO (2009) has reported that the bromide ion is found to involve in reaction between chlorine and naturally occurring organic matter in drinking water, forming brominated and mixed chlorobromo by-products (WHO 2009). However, Liu and Zhang (2014) have reported that 2-bromo-4-chlorophenol was toxic to a heterotrophic marine polychaete (Platynereis dumerilii) and marine alga (Tetraselmis marina). The haloacetic acids and trihalomethanes have indicated that the emerging halophenolic DBPs deserve more attention (Zha et al. 2014). The highest value of TDS, chloride, COD, TOC, chlorite and iodate was observed in the water samples collected from Srirangam and Tiruchirappalli which was significantly higher than that of the control water sample. The concentration of bromate was comparatively higher in Tiruchirappalli than Srirangam but significantly higher than that of control water sample. An increase in the level of these parameters forms the basis for DBPs formation.

\section{Conclusion}

More efforts must be taken to minimize the concentrations of disinfectants and DBPs without compromising in any way in the removal or inactivation of pathogens in the drinking water. Regarding the DBPs wax column and pentane liquid-liquid extraction employing pentane has resulted in the detection of the presence of 4-bromo2 -chlorophenol in the corporation water samples.

Acknowledgements The authors are thankful to, UGC-NON SAP, UGC-SAP and DST-FIST Govt. of India, New Delhi for the financial assistance provided to our department. 
Table 2 GC-MS analysis of water samples extracted using different solvents

\begin{tabular}{|c|c|c|c|c|c|}
\hline Peak number & $\begin{array}{l}\text { Sampling stations } \\
\text { and solvents }\end{array}$ & Compound name & Molecular formula & $\begin{array}{l}\text { Molecular } \\
\text { weight }\end{array}$ & $\begin{array}{l}\text { Total } \% \text { of } \\
\text { compounds }\end{array}$ \\
\hline 1 & T-PEN & 4-Bromo-2-chlorophenol ${ }^{\mathrm{a}}$ & $\mathrm{C}_{6} \mathrm{H}_{4} \mathrm{BrClO}$ & 206 & 89.975 \\
\hline 2 & T-PEN & 4-Bromo-2-chlorophenol ${ }^{\mathrm{a}}$ & $\mathrm{C}_{6} \mathrm{H}_{4} \mathrm{BrClO}$ & 206 & 29.257 \\
\hline 3 & T-PEN & 2,4,6-Trichlorobenzonitrile & $\mathrm{C}_{7} \mathrm{H}_{2} \mathrm{Cl}_{3} \mathrm{~N}$ & 208 & 07.467 \\
\hline 4 & S-PEN & 4-Bromo-2-chlorophenol ${ }^{\mathrm{a}}$ & $\mathrm{C}_{6} \mathrm{H}_{4} \mathrm{BrClO}$ & 206 & 18.109 \\
\hline 5 & S-PEN & Acetamide, $N$-(4-bromo-2-chlorophenyl)- & $\mathrm{C}_{8} \mathrm{H}_{7} \mathrm{BrClNO}$ & 248 & 05.794 \\
\hline 6 & S-PEN & 4-Bromo-2-chlorophenol ${ }^{\mathrm{a}}$ & $\mathrm{C}_{6} \mathrm{H}_{4} \mathrm{BrClO}$ & 206 & 25.391 \\
\hline 7 & S-PEN & 1,2,4-Trimethylbenzene & $\mathrm{C}_{9} \mathrm{H}_{12}$ & 120 & 02.426 \\
\hline 8 & C-PEN & 4-Bromo-2-chlorophenol ${ }^{\mathrm{a}}$ & $\mathrm{C}_{6} \mathrm{H}_{4} \mathrm{BrClO}$ & 206 & 35.097 \\
\hline 9 & C-PEN & 4-Bromo-3-chloroaniline & $\mathrm{C}_{10} \mathrm{H} 14$ & 134 & 07.586 \\
\hline 10 & T-HEX & Benzenamine, 4-bromo-2-chlorophenol & $\mathrm{C}_{9} \mathrm{H}_{12}$ & 120 & 07.774 \\
\hline 11 & T-HEX & 2,4,6-Trichlorobenzonitrile & $\mathrm{C}_{7} \mathrm{H}_{2} \mathrm{Cl}_{3} \mathrm{~N}$ & 208 & 05.540 \\
\hline 12 & T-HEX & 4-Bromo-3-chloroacetanilide & $\mathrm{C}_{8} \mathrm{H}_{7} \mathrm{BrClNO}$ & 248 & 13.502 \\
\hline 13 & S-HEX & Ethanesulfonyl chloride, 2-chloro & $\mathrm{C}_{2} \mathrm{H}_{4} \mathrm{Cl}_{2} \mathrm{O}_{2} \mathrm{~S}$ & 268 & 06.087 \\
\hline 14 & S-HEX & 4-Bromo-2-chlorophenol ${ }^{\mathrm{a}}$ & $\mathrm{C}_{6} \mathrm{H}_{4} \mathrm{BrClO}$ & 206 & 40.410 \\
\hline 15 & C-HEX & 3,4-Dichlorophenethylamine & $\mathrm{C}_{6} \mathrm{H}_{4} \mathrm{ClIO}$ & 142 & 07.681 \\
\hline 16 & C-HEX & 4-Chloro-2-iodophenol & $\mathrm{C}_{6} \mathrm{H}_{4} \mathrm{ClIO}$ & 142 & 02.807 \\
\hline 17 & T-PET & Chloromethanesulfonyl chloride & $\mathrm{C}_{2} \mathrm{HCl}_{3} \mathrm{O}_{2}$ & 148 & 12.554 \\
\hline 18 & S-PET & Trichloroacetic acid & $\mathrm{C}_{2} \mathrm{HCl}_{3} \mathrm{O}_{2}$ & 163 & 11.592 \\
\hline 19 & S-PET & Benzene, 1-bromo-3-chloro-2-methyl- & $\mathrm{C}_{7} \mathrm{H}_{6} \mathrm{BrCl}$ & 205 & 03.213 \\
\hline 20 & C-PET & Pentanoic acid, 3-methyl- & $\mathrm{C}_{6} \mathrm{H}_{12} \mathrm{O}_{2}$ & 116 & 01.450 \\
\hline 21 & C-PET & Benzene, 1-bromo-3-chloro-2-methyl- & $\mathrm{C}_{7} \mathrm{H}_{6} \mathrm{BrCl}$ & 205 & 02.215 \\
\hline 22 & C-PET & Heptanoic acid & $\mathrm{C}_{7} \mathrm{H}_{14} \mathrm{O}_{2}$ & 130 & 08.252 \\
\hline
\end{tabular}

$T$ Tiruchirappalli, $S$ Srirangam, $C$ control (before chlorination), $P E N$ pentane, $H E X$ hexane, $P E T$ petroleum ether (T-PEN: samples collected from Tiruchirappalli and extracted using pentane solvents)

${ }^{a}$ Halogenated DBP compound (4-bromo-2-chlorophenol) was identified at different places using various solvents

Funding Funding was provided by Department of Science and Technology, New Delhi (File No. DST/TM/WTI/2k14/166).

\section{Compliance with ethical standards}

Conflict of interest The authors declare no conflict of interest.

Open Access This article is distributed under the terms of the Creative Commons Attribution 4.0 International License (http://creativeco mmons.org/licenses/by/4.0/), which permits unrestricted use, distribution, and reproduction in any medium, provided you give appropriate credit to the original author(s) and the source, provide a link to the Creative Commons license, and indicate if changes were made.

\section{References}

Acero J, Piriou P, von Gunten U (2005) Kinetics and mechanisms of formation of bromophenols during drinking water chlorination: assessment of taste and odor development. Water Res 39:2979-2993

Agency for Toxic Substances and Disease Registry (ATSDR) (1999) Toxicological profile for chlorophenols. U.S. Department of Health and Human Services, Public Health Service, Atlanta
American Public Health Association (APHA) (1995) Standard methods for the examination of water and wastewater, 19th edn. APHA/ American Water Works Association/Water Pollution Control Federation, Washington

American Public Health Association (APHA) (2005) Standard methods for the examination of water and wastewater, 21st edn. APHA/ American Water Works Association and Water Environment Federation, Washington

Gaffga NH, Tauxe RV, Mintz ED (2007) Cholera: a new homeland in Africa? Am J Trop Med Hyg 77:705-713

Hur J, Lee M, Song H, Schlatman M (2012) Microbial transformation of dissolved organic matter from different sources and its influence on disinfection byproduct formation potentials. Environ Sci Pollut Res 20:4176-4187

Jiang J, Zhang X, Zhu X, Li Y (2017) Removal of intermediate aromatic halogenated DBPs by activated carbon adsorption: a new approach to controlling halogenated DBPs in chlorinated drinking water. Environ Sci Technol 51:3435-3444

Kitis M, Karanfil T, Kilduff JE, Wigton A (2001) The reactivity of natural organic matter to disinfection by-products formation and its relation to specific ultraviolet absorbance. Water Sci Technol 43:9-16

Krasner SW (2009) The formation and control of emerging disinfection by-products of health concern 367:4077-4095

Krasner SW, McGuire MJ, Jacangelo JG, Patania NL, Reagan KM, Aieta EM (1989) The occurrence of disinfection by-products in US drinking water. J Am Water Works Assoc 81:41-53

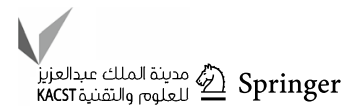


Liu J, Zhang X (2014) Comparative toxicity of new halophenolic DBPs in chlorinated saline wastewater effluents against a marine alga: halophenolic DBPs are generally more toxic than haloaliphatic ones. Water Res 65:64-72

Metcalf E (2003) Wastewater engineering treatment and reuse, vol 2-6, 4th edn. Tata McGraw-Hill, New Delhi, p 94

Nawrocki J (2013) Analysis of water disinfection by-products, vol 24. Department of Water Treatment Technology, Faculty of Chemistry, Adam Mickeiwiez University, Pozani, pp 60-613. www. pg.gda.pl/chem/CEEAM/Dokumenty/CEEAM.../chapter15.pdf

Paull B, Barron L (2004) Using ion chromatography to monitor haloacetic acids in drinking water: a review of current technologies. J Chromatogr A 1046:1-9

Pontius FW (1993) Disinfection by-products—a regulatory balancing act. Am Water Works Assoc 19:1-5

Prabhakaran D, Kannadasan T, Ahmed Basha C (2009) Mediated electrochemical oxidation process for destruction of TOC in a batch recirculation reactor. Int J Chem Technol Res 4:962-969

Richardson SD (2002) The role of GC-MS and LC-MS in the discovery of drinking water disinfection by-products. J Environ Monit 4:1-9

Rook JJ (1974) Formation of halo forms during chlorination of natural waters. Water Treat Exam 23:234-243

Sithole BB, Wiliams DT (1986) Halogenated phenols in water at fort Canadian potable water treatment facilities. J Assoc Off Anal Chem 69:807-810

The BIS has framed a set of standards for drinking water description (IS 10500:1991) (July, 2010). http://www.indiawaterportal.org/ articles/indian-standard-drinking-water-bis-specifications-10500 $-1991$

United States Environmental Protection Agency (2003) National primary drinking waters standard. United States Environmental Protection Agency, Washington

USEPA (US Environmental Protection Agency) (2006) National primary drinking water regulations: stage 2 disinfectants and disinfection byproducts rule: final rule. Fed Reg 71(2):388
Villanueva CM, Cordier S, Font-Ribera L, Sales LA, Levallois P (2015) Overview of disinfection by-products and associated health effects. Curr Environ Health Rep 2:107-115

Weisel CP, Kim H, Haltmeier P, Klotz JB (1999) Exposure estimates to disinfection by-products of chlorinated drinking water. Environ Health Perspect 107:103-110

WHO (2003) Cholera, 2002. Wkly Epidemiol Rec 78:269-276

WHO (2004) Environmental health criteria 216: disinfectants and disinfectant by-products, chapter 2. WHO, Geneva

WHO (2009) Bromide in drinking-water background document for development of WHO guidelines for drinking-water quality. http:// whqlibdoc.who.int/publications2011/9789241548151_eng.pdf

Yang M, Zhang X (2013) Comparative developmental toxicity of new aromatic halogenated DBPs in a chlorinated saline sewage effluent to the marine polychaete Platynereis dumerilii. Environ Sci Technol 47:10868-10876

Zeng Q, Zhang SH, Liao J, Miao DY, Wang XY, Yang P, Yun LJ, Liu AL, Lu WQ (2015) Evaluation of genotoxic effects caused by extracts of chlorinated drinking water using a combination of three different bioassays. J Hazard Mater 296:23-29

Zha X, Liu Y, Zhang Q, Dai R, Ying LK, Wu J, Wang J, Ma L (2014) Effects of bromide and iodide ions on the formation of disinfection by-products during ozonation and subsequent chlorination of water containing biological source matters. Environ Sci Pollut Res 21:2714-2723

Zhai H, Zhang X, Zhu X, Liu J, Ji M (2014) Formation of brominated disinfection byproducts during chloramination of drinking water: new polar species and overall kinetics. Environ Sci Technol 48:2579-2588

Publisher's Note Springer Nature remains neutral with regard to jurisdictional claims in published maps and institutional affiliations. 